九州大学学術情報リポジトリ

Kyushu University Institutional Repository

\title{
Evaluation of Finger-jointed Laminae for Glulam Timber by Acousitic Emission II Development of
} Evaluation System for Finger-jointed Laminae with Starved Joints

\section{Sato, Eri}

Graduate School of Research Divisions of Education, Technology Education, Fukuoka University of Education

\section{Ohuchi, Takeshi}

Laboratory of Wood Working, Department of Technology, Fukuoka University of Education

Fujimoto, Noboru

Laboratory of Wood Material Technology, Division of Biomaterial Science, Department of Forest and Forest Products Sciences, Faculty of Agriculture, Kyushu University

https://doi.org/10.5109/16133

出版情報: 九州大学大学院農学研究院紀要. 54 (2)，pp.471-475，2009-10-29. Faculty of Agriculture, Kyushu University

バージョン：

権利関係 : 


\title{
Evaluation of Finger-jointed Laminae for Glulam Timber by Acoustic Emission II Development of Evaluation System for Finger-jointed Laminae with Starved Joints
}

\author{
Eri SATO ${ }^{1}$, Takeshi OHUCHI*2 and Noboru FUJIMOTO ${ }^{3}$
}

\author{
Laboratory of Wood Material Technology, Division of Biomaterial Science, Department of Forest and \\ Forest Products Sciences, Faculty of Agriculture, Kyushu University, \\ Fukuoka 812-8581, Japanese \\ (Received June 30, 2009 and accepted July 13, 2009)
}

\begin{abstract}
In our previous studies, we paid attention to acoustic emission (AE) as a non-destructive method, and bending test for finger-jointed laminae with starved joints was performed. In addition, for installing the AE monitoring method into the production line of the finger-jointed laminae, a special attachment (jig) for the $\mathrm{AE}$ sensor installed into the production line was developed. However, this method with the jig was not efficient for the following two reasons; first, it is difficult to set the position of the jig. Secondly, it is necessary to stop the production line for the bending process.

In this study, the new type jig which installed the AE sensor for the detection of the laminae with starved joints regardless of both the position and the number of finger-joint parts is designed, and the evaluation tests of finger-jointed laminae were conducted by using this jig. That is, the evaluation system which installed the jig was constructed, and hinoki (Chamaecyparis obtua) finger-jointed laminae with starved joints were prepared, and the evaluation tests of finger-joint properties were conducted by using this system. The main results are summarized as follows: The evaluation system for the finger-jointed laminae was constructed. This system was composed of the motive power part, the AE measurement part, and the data collection part which controls some devices and collects sampling data. For the laminae with starved joints, the peak of $\mathrm{AE}$ signals which were measured by this system corresponded to the position of starved joints in the finger-jointed laminae. In addition, for the laminae with defects such as knots and loosed grain, the peak of $\mathrm{AE}$ signals which were measured besides the finger-joint part corresponded to the position of defects. From these results, this evaluation system which installed the jig with $\mathrm{AE}$ sensor was promising for detecting of the starved joints and the presence of defects in the finger-jointed laminae. It was found that modulus of elasticity (MOE) of the lamine during the evaluation test with this system could be measured in the grasp of the section size of the laminae beforehand. Therefore, it was suggested that the grading for the laminae after finger-jointing based on MOE could be possible by this system.
\end{abstract}

\section{INTRODUCTION}

The laminae that comprise glulam timber are generally finger-jointed. However, laminae with starved joints in the finger-joint are occasionally found in the manufacture of glulam timber, and greatly decrease the timbers' strength. Therefore, for the manufacture of glulam timber with good strength properties, the evaluation of finger-joint properties after finger-jointing is important, and the method is hoped to be simple and non-destructive.

In our previous studies, we paid attention to acoustic emission (AE) as a non-destructive method, and bending test for finger-joint laminae with starved joints was performed. We clarified that $\mathrm{AE}$ generated during the bending test was promising for the detection of starved joints in the finger-joint at the early stage of the bending test. In addition, it became clear that the position of starved joints in finger-joint could be presumed by one-

${ }^{1}$ Graduate School of Research Divisions of Education, Technology Education, Fukuoka University of Education

Laboratory of Woodworking, Department of Technology, Fukuoka University of Education

Laboratory of Wood Material Technology, Division of Biomaterial Science, Department of Forest and Forest Products Sciences, Faculty of Agriculture, Kyushu University

* Corresponding author (E-mail: tohuchi@fukuoka-edu.ac.jp) dimensional method of using AE signal (Ohuchi et al., 2004: Yano et al., 2007). Furthermore, in consideration of installing the $\mathrm{AE}$ monitoring method into the production line of the finger-joint laminae, a special attachment (jig) for the $\mathrm{AE}$ sensor installed into the production line was developed. From the result of verification test with the jig, it was clear that the possibility of the detection of the starved joints by $\mathrm{AE}$ as a non-destructive method was suggested in the case of loading to the finger-jointed part of laminae in $4 \mathrm{kN}$ as the detection load with the jig (Ohuchi et al., 2009). However, it was pointed out that this method with the jig was not efficient for the following two reasons; first, it is difficult to set the position of the jig beforehand because neither the position nor the number of finger-joint parts in the laminae is decided. Secondly, it is necessary to stop the production line for the bending process.

In this study, the main objective was to develop the evaluation method for detecting of the laminae with starved joints without stopping the production line regardless of both the position and the number of fingerjoint parts in the laminae. In this report, the new type attachment (jig) which installed the AE sensor as nondestructive method for the detection of the laminae with starved joints is designed, and the evaluation tests of finger-jointed laminae were conducted by using this jig. That is, the evaluation system which installed the new 
jig was constructed, and hinoki (Chamaecyparis obtua) finger-jointed laminae with starved joints were prepared, and the evaluation tests of finger-joint properties were conducted by using this system.

\section{MATERIALS AND METHODS}

\section{Specimens}

Specimens used in this study were made from hinoki (Chamaecyparis obtua) laminae. The mean specific gravities and the mean moisture contents of specimens were 0.53 and $12.5 \%$, respectively. These laminae were sorted not to have any knots or faults within $100 \mathrm{~mm}$ of the tip of finger-joint, and short-length laminae were made. The profile of the finger-joint was as shown in Fig. 1, where $\mathrm{l}=14.0 \mathrm{~mm}, \mathrm{p}=3.9 \mathrm{~mm}, \mathrm{t} 1=0.7 \mathrm{~mm}, \mathrm{t} 2=$ $0.6 \mathrm{~mm}$, and $\theta=4$ in 98 . These laminae were fingerjointed using aqueous polymer solution-isocyanate adhesive for wood (API) and end pressed at $9.2 \mathrm{~N} / \mathrm{mm}^{2}$. The finger-jointed laminae without starved joints were used as control specimens and assumed to be C-laminae. On the other hand, the finger-jointed laminae without curing agent (hardener) were used and assumed to be NH-laminae. These finger-jointed methods were the same as those in our previous studies (Yano et al., 2007; Ohuchi et al., 2009). These two kinds of finger-jointed laminae were $113 \mathrm{~mm}$ wide, $20 \mathrm{~mm}$ thick, and $2000 \mathrm{~mm}$ long as shown in Fig. 2. Furthermore, these fingerjointed laminae have from 3 to 4 finger-joint parts.

\section{Evaluation system}

The schematic diagram of the evaluation system for finger-jointed laminae is shown in Fig. 3 and the block chart is shown in Fig. 4. This evaluation system was composed of three parts. The first part is the motive power

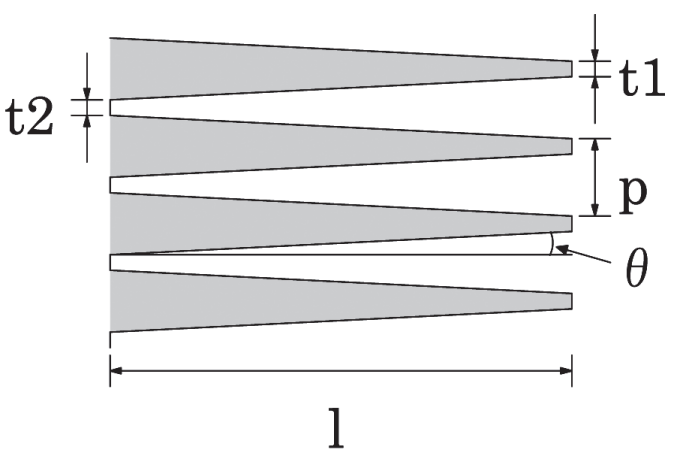

Fig. 1. Profile of the finger-joint.

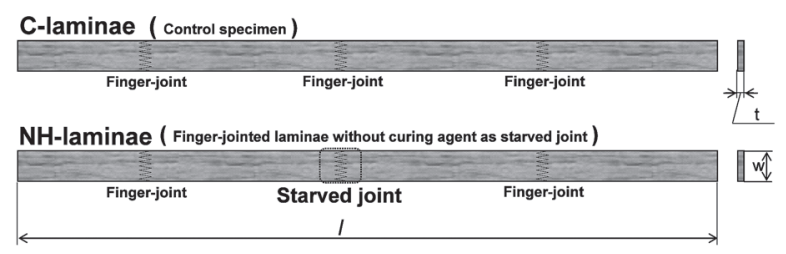

Fig. 2. Types of specimens with- and without starved joints (C- and NH-laminae). part for the hydraulic pomp and cylinder. The hydraulic cylinder head is made to go up and down, and the deflection is given to the finger-jointed laminae. The second part is the $\mathrm{AE}$ measurement part. AE signals are measured by the new type attachment (jig) which installed the AE sensor. The jig was composed of the roller and the bearing frame mounted $\mathrm{AE}$ sensor. The third part is the data collection part. In this part, the load and the displacement under the evaluation test are measured, and these data and AE signals are collected with the personal computer (PC) through the analog to digital (AD) converter.

In the experiment, the connector for the wire of winch is installed in the edge of the finger-jointed laminae and the laminae is set under the jig. The hydraulic cylinder head is then downed and an arbitrary deflection is given to the laminae. The whole laminae are pulled with the winch and it flows on the evaluation system. The AE signals generated during the evaluation test were measured. In addition, the bending load and the dis-

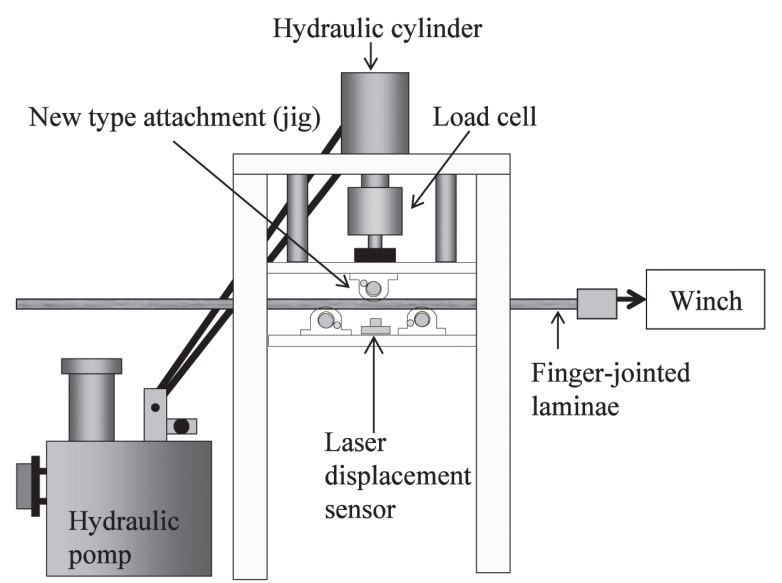

Fig. 3. Schematic diagram of evaluation system for finger-jointed laminae.

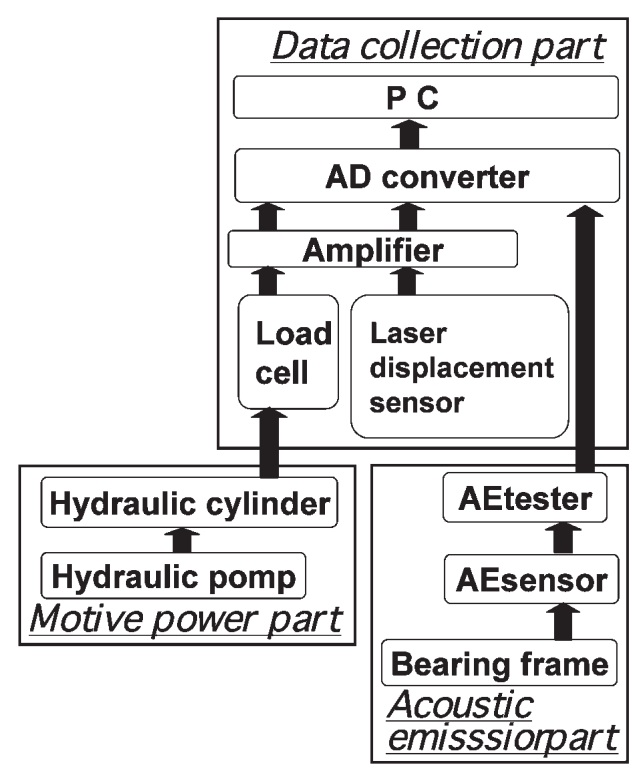

Fig. 4. Block chart of evaluation system. 
placement along with the laminae flowing on the evaluation system were measured.

\section{Evaluation test}

Evaluation tests for all $\mathrm{C}$ - and $\mathrm{NH}$-laminae were conducted by using this evaluation system. The deflection was set to $2,3,4$, and $5 \mathrm{~mm}$, respectively. The AE signals generated during tests were measured by three jigs and $\mathrm{AE}$ testers as shown in Fig. 5. In the $\mathrm{AE}$ measurement, the high-pass filter was set to $100 \mathrm{kHz}$ with the $\mathrm{AE}$ tester. The $\mathrm{AE}$ signals received with the jig were amplified to $66 \mathrm{~dB}$ and the threshold level was $100 \mathrm{mV}$ with the $\mathrm{AE}$ tester. The resonance frequency of the $\mathrm{AE}$ sensor was $140 \mathrm{kHz}$. Thus, the $\mathrm{AE}$ average signal and the AE accumulated signal were measured under the abovementioned measurement conditions. The bending load due to the deflection was measured with the load cell installed into the hydraulic cylinder head.

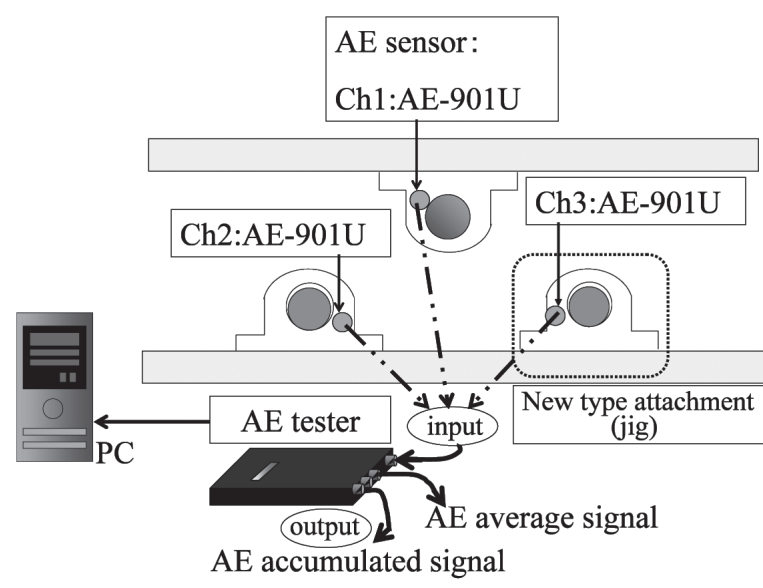

Fig. 5. Outline of new type attachment (jig) with AE sensor.

\section{RESULTS AND DISCUSSION}

\section{Behavior of AE generation}

The typical waveforms of $\mathrm{AE}$ signals (AE average signal and $\mathrm{AE}$ accumulated signal) in $\mathrm{NH}$-laminae obtained in this evaluation test are shown in Fig. 6. The $\mathrm{X}$ axis in this Figure shows the time under the evaluation test. That is, the time is considered the same as the length of the finger-jointed laminae. The peak of both waveforms was recognized. Based on the peak time, the position of laminae in which AE generated was verified. From this verification result, it was confirmed that the peak time and the starved joints part were corresponded. These results suggest that this system was promising for the detection of the starved joints part in the finger-jointed laminae.

Figure 7 shows the typical waveforms of AE average signal in NH-laminae within the range of deflection from 2 to $5 \mathrm{~mm}$. In the case of $2 \mathrm{~mm}$ in deflection, the change of the waveform was hardly recognized. However, when the deflection is larger than $3 \mathrm{~mm}$, the peak of the waveform corresponding to the starved joints part was recog-

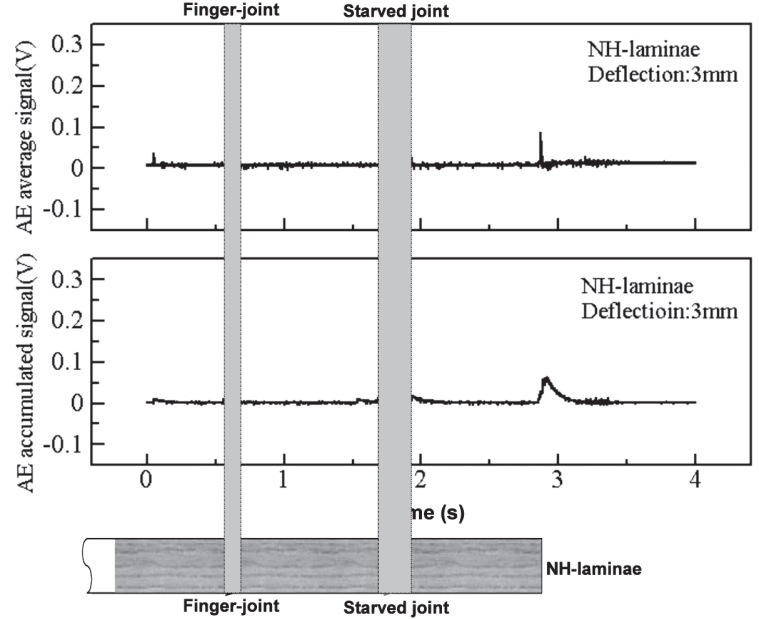

Fig. 6. Typical waveforms of AE signals in NH-laminae.

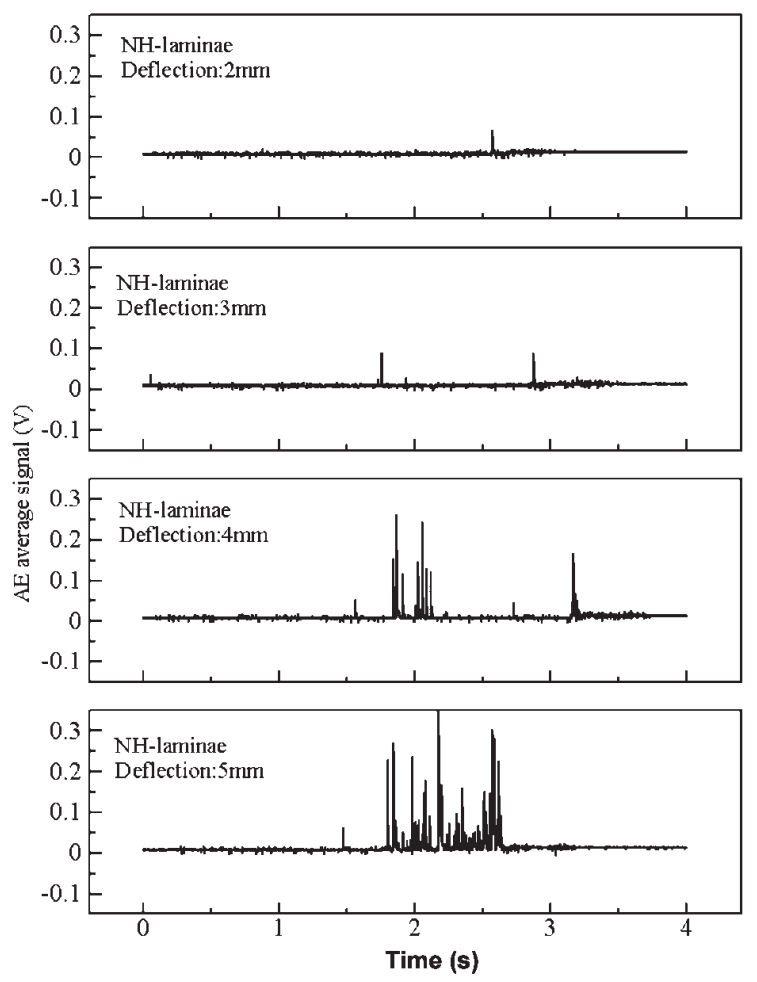

Fig. 7. Typical waveforms of $\mathrm{AE}$ average signal in NH-laminae within the range of deflection from 2 to $5 \mathrm{~mm}$.

nized. In addition, the amplitude of the peak showed the tendency to increase with increasing the deflection. Then, in starved joints part of each NH-laminae, the time in which AE signals were remarkably generated (continuance time) and the maximum value during the continuance time were examined, and the mean value of each deflection was calculated. The result is shown in Table. 1. The maximum value of $\mathrm{AE}$ average signal showed the tendency to increase with increasing the deflection. Moreover, the difference of the continuance time of $\mathrm{AE}$ average signal and the maximum value and the continuance time of $\mathrm{AE}$ accumulated signal was hardly recognized in the cases of $3 \mathrm{~mm}$ and $4 \mathrm{~mm}$ in deflection, 
Table 1. Maximum value and continuance time of $\mathrm{AE}$ signals in NH-laminae

\begin{tabular}{cccccc}
\hline \multirow{2}{*}{$\begin{array}{c}\text { Deflection } \\
(\mathrm{mm})\end{array}$} & \multicolumn{2}{c}{ AE average signal } & & \multicolumn{2}{c}{ AE accumulated signal } \\
\cline { 6 - 6 } \cline { 5 - 6 } & $\begin{array}{c}\text { Maximum } \\
\text { value }(\mathrm{V})\end{array}$ & $\begin{array}{c}\text { Continuance } \\
\text { time }(\mathrm{S})\end{array}$ & & $\begin{array}{c}\text { Maximum } \\
\text { value }(\mathrm{V})\end{array}$ & $\begin{array}{c}\text { Continuance } \\
\text { time }(\mathrm{S})\end{array}$ \\
\hline 3 & 0.07 & 0.10 & & 0.05 & 0.37 \\
4 & 0.18 & 0.11 & & 0.04 & 0.39 \\
5 & 0.36 & 0.66 & & 0.08 & 1.03 \\
\hline
\end{tabular}

and the values of those in the case of $5 \mathrm{~mm}$ in deflection showed the tendency to increase. In this evaluation test, in the cases of $4 \mathrm{~mm}$ and $5 \mathrm{~mm}$ in deflection, the rupture in the starved joints part in NH-laminae was often occurred. In especially, these ruptures were admitted in the case of $5 \mathrm{~mm}$ in deflection. It is considered that $\mathrm{AE}$ signals in the case of $5 \mathrm{~mm}$ were remarkably generated because of these ruptures. Therefore, it became clear that the optimum deflection in this evaluation test is $3 \mathrm{~mm}$. In addition, a remarkable difference between the maximum value of $\mathrm{AE}$ average signal in the case of $3 \mathrm{~mm}$ and $4 \mathrm{~mm}$ in deflection was recognized. Therefore, the result was suggested to be able to detect the starved joints part in the finger-jointed laminae by setting the deflection to $3 \mathrm{~mm}$ and the threshold to $0.1 \mathrm{~V}$ for the $\mathrm{AE}$ average signal.

\section{Detection of knot and loosed grain}

Figure 8 shows the typical waveforms of AE average signal and $\mathrm{AE}$ accumulated signal that the peaks were recognized at the position besides the finger-joint part in the C-laminae. From the result of the observation of these laminae after the evaluation tests, knots and defects such as loosed grain were confirmed, and it became clear that these positions in the laminae corresponded to the peak of both the typical waveforms as shown in Fig. 8. It is considered that $\mathrm{AE}$ was generated because the slight rupture occurred in the vicinity of the knots and loosed grain when the deflection was given to the laminae. From above results, it was found that this evaluation system could recognize the presence of knots and loosed grain in the finger-jointed laminae.

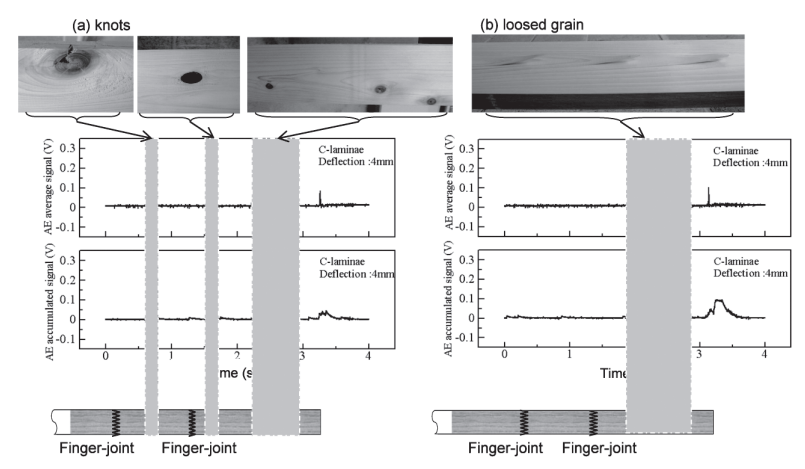

Fig. 8. Typical waveform of $\mathrm{AE}$ signals that the peaks were recognized at the position besides the finger-joint part in C-laminae.

\section{Bending strength properties}

Figure 9 shows the typical waveform of load of $\mathrm{NH}$-laminae in the case of $2 \mathrm{~mm}$ in deflection. Thus, a change of the load value was admitted. The change in this load is ascribable to the difference of the strength properties of each short-length laminae, and the position in which this change occurred corresponded to the finger-joint part. Therefore, it was suggested to be able to presume the position of the finger-joint part from this change of the waveform of load.

The load measured by this evaluation system when the deflection is given to the finger-jointed laminae corresponded to the bending load as mentioned above. Therefore, the modulus of elasticity (MOE) of the laminae can be calculated from the bending load, the section size of the laminae, and the deflection during the evaluation test. Then, the bending load of three short-length laminae (NH-1, NH-2, NH-3) in $\mathrm{NH}-$ laminae was examined from the waveform as shown in Fig. 9, respectively. In addition, the section size of laminae was measured, and MOE for each short-length laminae was calculated, respectively. Moreover, to verify these values, the specimens for the bending test were made from three shortlength laminae. A static bending test was conducted by using a Universal Testing Machine. Three point bending was applied over an effective span of $190 \mathrm{~mm}$ at a loading speed of $5 \mathrm{~mm} / \mathrm{min}$. From the result of the bending test, MOE for each three short-length laminae was calculated, respectively. Figure 10 shows the result of both MOE. Thus, both MOE showed almost the same value. From the result, it became clear that MOE of the lamine during the evaluation test by this system could be meas-

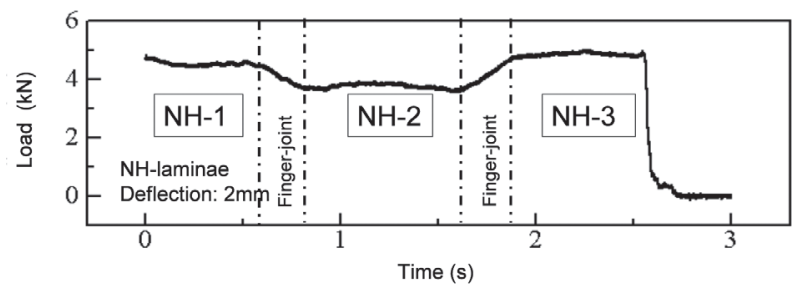

Fig. 9. Typical waveform of load in NH-laminae.

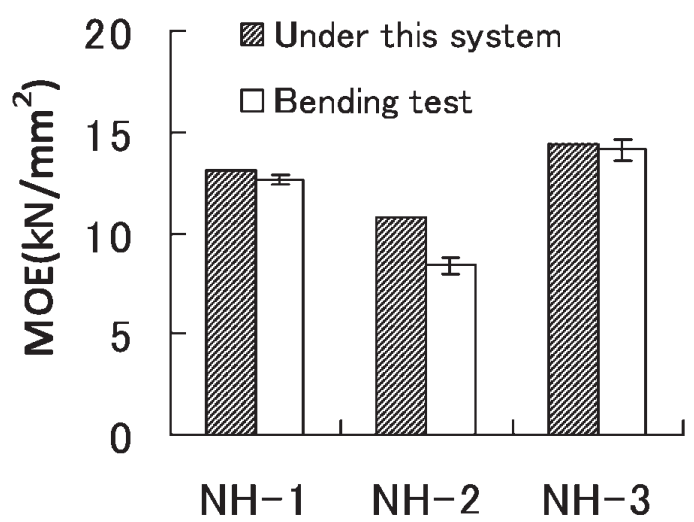

Fig. 10. MOE for each short-length laminae. 
ured in the grasp of the section size of the laminae beforehand. Therefore, it was suggested that the grading for the laminae after finger-jointing based on MOE by this system could be possible.

\section{CONCLUSIONS}

In this study, the new type attachment (jig) which installed the AE sensor as non-destructive method for the detection of the laminae with starved joints is designed, and the evaluation tests of finger-jointed laminae were conducted by using this jig. That is, the evaluation system which installed the new jig was constructed, and hinoki finger-jointed laminae with starved joints were prepared, and the evaluation tests of finger-joint properties were conducted by using this system. The main results are summarized as follows:

1) The evaluation system for the finger-jointed laminae was constructed. This system was composed of three parts. The first part is the motive power part for the hydraulic pomp and cylinder. The second part is the AE measurement part. The third part is the data collection part which controls some devices and collects sampling data.

2) For the laminae with starved joints, the peak of $\mathrm{AE}$ signals which were measured by this evaluation system corresponded to the position of starved joints in the finger-jointed laminae. From the result, this sys- tem which installed the jig with $\mathrm{AE}$ sensor was promising for detecting of the starved joints

3) The peak of AE signals which were measured besides the finger-joint part corresponded to the position of both knots and loosed grain. Therefore, this system was promising for detecting of the presence of defects as such knots and loosed grain in the laminae.

4) It was found that MOE of the lamine during the evaluation test by this system could be measured in the grasp of the section size of the laminae beforehand. Therefore, it was suggested that the grading for the laminae after finger-jointing based on MOE could be possible by this system.

\section{REFERENCES}

Ohuchi T, Ando M, Fujimoto Y, Morita, Fujimoto N, Murase Y 2004 Non-destructive evaluation of strength properties of sugi finger-jointed laminae (in Japanese). The summary of the 22nd Wood Technological Association of Japan (Osaka): 85-86

Ohuchi T, Murakami Y, Fujimoto N 2009 Evaluation of fingerjointed laminae for glulam timber by acoustic emission I Development of jig for acoustic emission sensor installed to production line and its verification test. Journal of the Faculty of Agriculture Kyushu University, in submitting

Yano K, Ohuchi T, Murase Y, Fujimoto Y, Morita H 2007 Evaluation of sugi finger-jointed laminae with a knot and starved joints by acoustic emission. Journal of the Faculty of Agriculture Kyushu University, 52(1): 111-116 